\title{
Consumo Voluntário, Digestibilidade e Balanço de Nitrogênio em Ovinos Recebendo Palha de Arroz Amonizada em Diferentes Níveis de Oferta
}

\author{
Júlio Cesar Damasceno', Geraldo Tadeu dos Santos ${ }^{1}$, Ulysses Cecato', Eduardo Shiguero \\ Sakaguti ${ }^{1}$, Claudete Regina Alcalde ${ }^{1}$, Antonio Ferriani Branco ${ }^{1}$
}

\begin{abstract}
RESUMO - Foi realizado um experimento com o objetivo de estudar os efeitos de níveis de oferta de palha de arroz amonizada com uréia no consumo voluntário (CMS) e na digestibilidade da matéria seca (DMS) e no consumo, na excreção, na digestibilidade e no balanço de N. Foram utilizados 15 ovinos adultos, machos, castrados, com peso médio de 63,8 kg, mantidos individualmente em gaiolas metabólicas. Os níveis de oferta de palha utilizados foram: 1,5; 3,0; 4,5; 6,0; e 7,5\% do peso vivo (PV). Um suplemento (200 g/animal/ dia de milho) foi utilizado para fornecer energia disponível aos microrganismos do rúmen. Não houve efeito do nível de oferta de palha sobre a DMS, a excreção de $\mathrm{N}$ na urina, a digestibilidade do $\mathrm{N}$ e o balanço de $\mathrm{N}$, sendo os valores médios de 58,6\%, 8,23 g/dia, 44,74\% e 0,29 g/dia, respectivamente. Houve efeito linear do nível de oferta no consumo e excreção de N nas fezes. Os consumos de MS e MS digestível (MSD) aumentaram linearmente até os níveis de oferta de 3,0 e 4,3\%, respectivamente. Estes níveis de oferta resultaram em 23,9 e 37,4\% de sobras, respectivamente. Baseando-se no consumo de MSD acima das exigências de mantença $\left(0,12\right.$ energia digestível Mcal $\left./ \mathrm{kgPV}^{0,75}\right)$, para maximizar o desempenho por unidade de palha ofertada, recomenda-se fornecer cerca de $123,05 \mathrm{~g} / \mathrm{kgPV}^{0,75} \mathrm{de} \mathrm{palha} \mathrm{de} \mathrm{arroz}$ amonizada. Quando o objetivo for apenas atender a mantença dos animais, níveis inferiores a $123,1 \mathrm{~g} / \mathrm{kgPV}^{0,75}$ são aceitos. Níveis superiores não são recomendados, pois haverá desperdício de palhas, sem haver incremento na resposta animal.
\end{abstract}

Palavras-chave: amonização, balanço de nitrogênio, consumo voluntário, digestibilidade, níveis de oferta, uréia

\section{Voluntary Intake, Digestibility and Nitrogen Balance in Sheep Fed Ammoniated Rice Straw in Different Allowance Levels}

\begin{abstract}
An experiment was conducted to study the effects of allowance of ammoniated rice straw on the voluntary intake (VI) and digestibility of dry matter (DMD), and on the intake, excretion, digestibility and $\mathrm{N}$ balance. Fifteen adult sheep, males, castrated, with average weight of $63.8 \mathrm{~kg}$, individually kept in metabolic cages, were used. The levels of straw fed to the animals were: $1.5 ; 3.0$; $4.5 ; 6.0$ and $7.5 \%$ of live weight. A supplement (200 g/animal/day of corn) was used to supply available energy to the ruminal microorganisms. There was no effect of the level of straw offer on DMD, excretion of $\mathrm{N}$ in the urine, digestibility and balance of the $\mathrm{N}$, and the average values were $58.6 \%, 8.23 \mathrm{~g} / \mathrm{day}, 44.7 \%$ and $0.29 \mathrm{~g} / \mathrm{day}$, respectively. There was linear effect of the offer level on the intake and excretion of $\mathrm{N}$ in the feces. The DM and DMDs intake linearly increased up to 3.0 and $4.3 \%$, respectively. These allowance levels produced 23.9 and $37.4 \%$ of orts, respectively. Based on the intake of DMD above the maintenance requirements ( 0.12 digestible energy $\mathrm{Mcal} / \mathrm{kgPV}^{0.75}$ ), to maximize the animal performance per unit of straw fed is recommended to supply about 123.05 $\mathrm{g} / \mathrm{kgPV}^{0.75}$ of ammoniated rice straw. When the objective is just to meet the maintenance requirement of the animals, levels lower than $123.05 \mathrm{~g} / \mathrm{kgPV}^{0.75}$ are accepted. Higher levels are not recommended, therefore there would be waste of straws without increment in the animal response.
\end{abstract}

Key Words: allowance levels, ammonization, digestibility, nitrogen balance, urea, voluntary intake

\section{Introdução}

Esforços têm sido despendidos por pesquisadores com o objetivo de incrementar a participação das palhas de cereais na alimentação de ruminantes, uma vez que se trata de material de baixo custo, freqüentemente desperdiçado pelos agricultores. A conversão destes resíduos em leite ou carne, por exemplo, resultaria em produção de grande quantidade de alimentos de qualidade para o homem.
O principal fator limitante do uso de palhas de cereais é o seu baixo valor nutritivo, com baixos teores de nitrogênio, digestibilidade reduzida e consumo voluntário inadequado, resultando em desempenhos insatisfatórios. Em virtude disto, tratamentos físicos, biológicos e químicos, ou a combinação destes, têm sido recomendados, sendo uma das alternativas a amonização via uréia, pois melhora a digestibilidade e eleva o teor de nitrogênio da palha (DAMASCENO et al., 1994). 
Um dos principais determinantes do desempenho animal é o consumo voluntário de alimento, indicando que este deve ser maximizado.

A quantidade de palha ofertada aos animais tem grande impacto sobre o consumo. Os valores máximos de consumo normalmente são alcançados com altos níveis de ofertas de palha, resultando em quantidades consideráveis de sobras, superiores aos 20,0\% freqüentemente considerados suficientes para atingir máximo consumo (WAHED et al., 1990; FERNANDES-RIVERA et al., 1994). Este comportamento é evidente em pequenos ruminantes, devido à sua capacidade de seleção e, também, ao fato de a palha estar constituída de várias frações que diferem em qualidade, embora haja evidências de que as folhas e caules da palha de arroz sejam de qualidade semelhante (OWEN e VELASQUES, 1992).

Trabalhos com palhas não-tratadas têm mostrado que o consumo de MS aumenta, à medida que a oferta de palha é incrementada, havendo respostas com níveis de oferta que resultem em sobras acima de 50,0\% (WAHED et al., 1990; FERNANDES-RIVERA et al., 1994). Esta estratégia tem sido recomendada como alternativa para melhorar a eficiência de utilização da palha, em substituição à amonização (OWEN e VELASQUES, 1992). Entretanto, seria arriscado descartar técnicas como a amonização, uma vez que o efeito de níveis de oferta não tem sido estudado com palhas tratadas. Outro aspecto importante a ser considerado é que, para caracterizar o valor nutritivo da palha amonizada, necessita-se de informações sobre o consumo potencial máximo, a digestibilidade da matéria seca (MS) e o balanço de nitrogênio em condições nas quais é permitido ao animal ampla oportunidade para selecionar o alimento (BOSMAN et al., 1995).

BOSMAN et al. (1995) sugerem que uma forma de medir o valor do alimento para produção animal é determinar a quantidade máxima de nutrientes digestíveis acima das exigências de mantença, que o animal ingeriria por unidade de alimento ofertado. Com base neste valor, o nível ótimo de oferta pode ser determinado.

Este experimento foi realizado para quantificar os efeitos dos níveis de oferta de palha de arroz amonizada nas seguintes variáveis: consumo voluntário e digestibilidade da MS; consumo, excreção, digestibilidade e balanço de $\mathrm{N}$; e nível crítico de oferta de palha que maximiza a eficiência de utilização da palha disponível.

\section{Material e Métodos}

O experimento foi realizado no Laboratório de Digestibilidade do Departamento de Zootecnia da Universidade Estadual de Maringá, Maringá, Paraná.

Foram utilizados 15 ovinos castrados, sem raça definida e peso médio de $63,8 \mathrm{~kg}$. Os animais foram mantidos em gaiolas metabólicas, tendo livre acesso à água e mistura mineral.

O volumoso utilizado foi a palha de arroz amonizada, utilizando-se uréia como fonte de amônia. A uréia (solução de $100 \mathrm{~g}$ de uréia/L) foi aplicada na proporção de 5,0\% da matéria seca de palha, sendo a umidade final da mistura palha e uréia de, aproximadamente, 35,0\% (DAMASCENO et al., 1994). A palha foi regada com a solução de uréia e armazenada em silos cilíndricos de concreto, vedados por um período mínimo de 20 dias. Antes de ser fornecida aos animais, a palha foi exposta ao ar por período de 48 horas, para perder o excesso de amônia, com o objetivo de evitar inibição do consumo voluntário de MS.

Os tratamentos corresponderam aos seguintes níveis de oferta de MS de palha: 1,5; 3,0; 4,5; 6,0; e $7,5 \%$ do peso vivo (PV) animal.

Além da palha, os animais receberam diariamente $200 \mathrm{~g}$ de milho moído, em duas porções (manhãe tarde), separadamente do volumoso, para garantir energia disponível aos microrganismos do rúmen. O volumoso foi fornecido três vezes ao dia, às $7 \mathrm{~h} 30,12 \mathrm{~h}$ e $17 \mathrm{~h} 30 \mathrm{~h}$.

A palha amonizada e o milho apresentaram $8,3 \mathrm{e}$ $9,8 \%$ de proteína bruta na matéria seca, respectivamente.

O período experimental compreendeu duas fases: adaptação e coleta.

Inicialmente, durante sete dias os animais receberam palha na quantidade de $1,5 \mathrm{~kg} / \mathrm{animal} / \mathrm{dia}$. No oitavo dia, os animais foram pesados e passaram a receber os tratamentos experimentais, adotando-se a partir deste momento o controle diário das sobras, até a estabilização do consumo. Após o $12^{\circ}$ dia de adaptação, iniciou-se a coleta de amostras.

A fase de coleta estendeu-se por sete dias, quando foram realizadas pesagens individuais, diariamente, do alimento fornecido, das sobras e das fezes, bem como a determinação do volume de urina excretada. Foram coletadas amostras diárias ( $20 \%$ do total) dos alimentos, das sobras, fezes e da urina. Nos coletores de urina, foram colocados $20 \mathrm{~mL}$ de ácido clorídrico (1:1) com o objetivo de se evitarem perdas de nitrogênio por volatilização. Após coletadas, as amostras foram acondicionadas em recipientes plásticos e congeladas, para posteriores análises. 
Foram realizadas análises em amostras compostas, resultantes de sete subamostras, individualmente para cada animal. Nas amostras de alimentos, sobras e fezes, foram determinados a MS e o nitrogênio total (NT) (ASSOCIATION OF OFFICIAL ANALYTICAL CHEMISTS - AOAC, 1990), enquanto nas amostras de urina, apenas o teor de NT (AOAC, 1990).

O delineamento experimental utilizado foi o inteiramente casualizado, com cinco tratamentos e três repetições. Os efeitos dos níveis de oferta na digestibilidade da MS e do N, no balanço de nitrogênio, no consumo e na excreção de $\mathrm{N}$ e no VPA (Valor para a Produção Animal) foram estudados mediante análise de regressão polinomial, segundo SNEDECOR e COCHRAN (1989).

Para o estudo dos efeitos dos tratamentos sobre o consumo de MS e MSD, seguiram-se os procedimentos descritos por FERNANDES-RIVERA et al. (1994) e BOSMAN et al. (1995).

Assumindo-se que, à medida que a oferta de palha aumenta, o consumo de MS e MSD incrementa até atingir um valor máximo, tendendo à assintota, a relação entre o consumo e a oferta foi descrita pelo modelo seguinte:

$$
Y=C_{\text {max }}\left(1-e^{-k . N O}\right)
$$

em que $Y$ é o consumo de MS (\%PV) ou de MSD (\%PV); $C_{\text {max }}$ o parâmetro estimado do modelo que representa o consumo potencial máximo (\%PV); e $k$, o parâmetro que representa o incremento no consumo, em relação a $C_{\text {max }}$, para cada unidade de aumento no nível de oferta $N O(\% \mathrm{PV})$.

O nível crítico de oferta $(N C)$, abaixo do qual o consumo $(Y)$ seria reduzido substancialmente, foi estimado por intermédio do seguinte modelo:

$Y=a-b(N C-N O)$ para $N O \leq N C$ e $Y=a$ para $N O>N C$ em que $a$ é o consumo de MS ou MSD na parte do plateau do modelo e $b$, a taxa com que o consumo varia em função da oferta, mas abaixo do nível crítico $(N C)$.

A relação entre as sobras (SMS) e a oferta de palha foi descrita pelo modelo:

$$
S M S=1-e^{-k 2(N O-O M)} \text { para } N O>O M \text { e } S M S=0
$$
para $N O \leq O M$.

em que $O M$ representa a oferta máxima para que nenhum alimento sobre e $k 2$, a taxa de incremento das sobras em relação à oferta de palha $(N O)$ acima de $O M$.

A determinação do nível de oferta que resulte em maior eficiência de utilização da palha foi feita utilizando-se a equação descrita por BOSMAN et al. (1995):

$$
\mathrm{VPA}=\left(\mathrm{CMSD}_{\text {tot }}-\mathrm{CMSD}_{\text {mant }}\right) / \mathrm{X}
$$

em que $V P A$ é o Valor para Produção Animal, o qual representa a MSD consumida disponível para a pro- dução, expressa como proporção da MS ofertada ( $X$, $\left.g / k g P V^{-0,75}\right) ; C M S D_{t o t}$, o consumo de matéria seca digestível diário $\left(\mathrm{g} / \mathrm{kg} \mathrm{PV}^{0,75}\right)$; e $C M S D_{\text {mant }}$, a quantidade de matéria seca digestível para atender às exigências de mantença $\left(\mathrm{g} / \mathrm{kg} \mathrm{PV}^{0,75}\right)$. Neste modelo, utilizou-se $\mathrm{g} / \mathrm{kg} \mathrm{PV} \mathrm{PV}^{0,75}$ como unidade, porque as exigências energéticas para mantença são expressas desta forma (NATIONAL RESEARCH COUNCIL - NRC, 1985). Assumiu-se que a exigência de energia digestível para mantença foi de 0,12 $\mathrm{Mcal} / \mathrm{kg} \mathrm{PV}^{0,75}$ (NRC, 1985) e que a MSD da palha de arroz amonizada teria valor energético de 4,4 $\mathrm{Mcal} / \mathrm{kg}$ de MS (valor energético dos carboidratos). Nesta análise, os níveis de oferta de palha foram expressos em relação ao peso metabólico dos animais, conforme descritos a seguir: 42,39; 84,79; 127,18; 169,57; e 211,96 g/kg PV ${ }^{0,75}$.

\section{Resultados e Discussão}

\section{Digestibilidade da matéria seca e balanço de nitrogênio}

Os valores de digestibilidade da MS e balanço de nitrogênio encontram-se na Tabela 1. Constata-se que não houve efeito do nível de oferta de palha sobre a digestibilidade da MS, sendo o valor médio desta variável de 58,6\%. Houve efeito linear do nível de palha ofertada $(\mathrm{P}<0,05)$ no consumo e na excreção de $\mathrm{N}$ nas fezes. Para cada unidade de incremento na oferta de palha, houve aumento de $1,09 \mathrm{~g}$ de $\mathrm{N}$ consumido e $0,778 \mathrm{~g}$ de $\mathrm{N}$ excretado nas fezes. O nitrogênio excretado na urina ( $\mathrm{N}-$ Urina), a digestibilidade do $\mathrm{N} \mathrm{e} \mathrm{o} \mathrm{N}$ retido não sofreram efeitos do nível de oferta de palha $(\mathrm{P}>0,05)$, sendo que os valores médios foram $8,23 \mathrm{~g} / \mathrm{dia}, 44,7 \%$ e $0,29 \mathrm{~g} / \mathrm{dia}$, respectivamente.

A ausência de efeitos da oferta de volumoso na digestibilidade da MS está de acordo com o obtido por BOSMAN et al. (1995), quando ofereceram leguminosas tropicais para caprinos em diferentes níveis. Já FERNANDEZ-RIVERA et al. (1994) obtiveram aumentos lineares na digestibilidade da MS e da MO, quando forneceram resíduos de Pennisetum glaucum em níveis crescentes a ovinos, sendo que a explicação para este fato seria a heterogeneidade do material quanto ao valor nutritivo das diferentes frações, que, fornecido em maiores quantidades aos animais, permitiu o consumo seletivo.

Na presente pesquisa, o volumoso utilizado foi a palha de arroz, que, aparentemente, não apresenta diferenças na composição das diferentes frações da planta (OWEN e VELÁSQUEZ, 1992), sendo talvez 
Tabela 1 - Digestibilidade da matéria seca (DMS), balanço e digestibilidade do nitrogênio, em função dos níveis de oferta de palha de arroz amonizada

Table 1 - Dry matter digestibility (DMD), balance and digestibility of the nitrogen in function of the ammoniated rice straw allowance levels

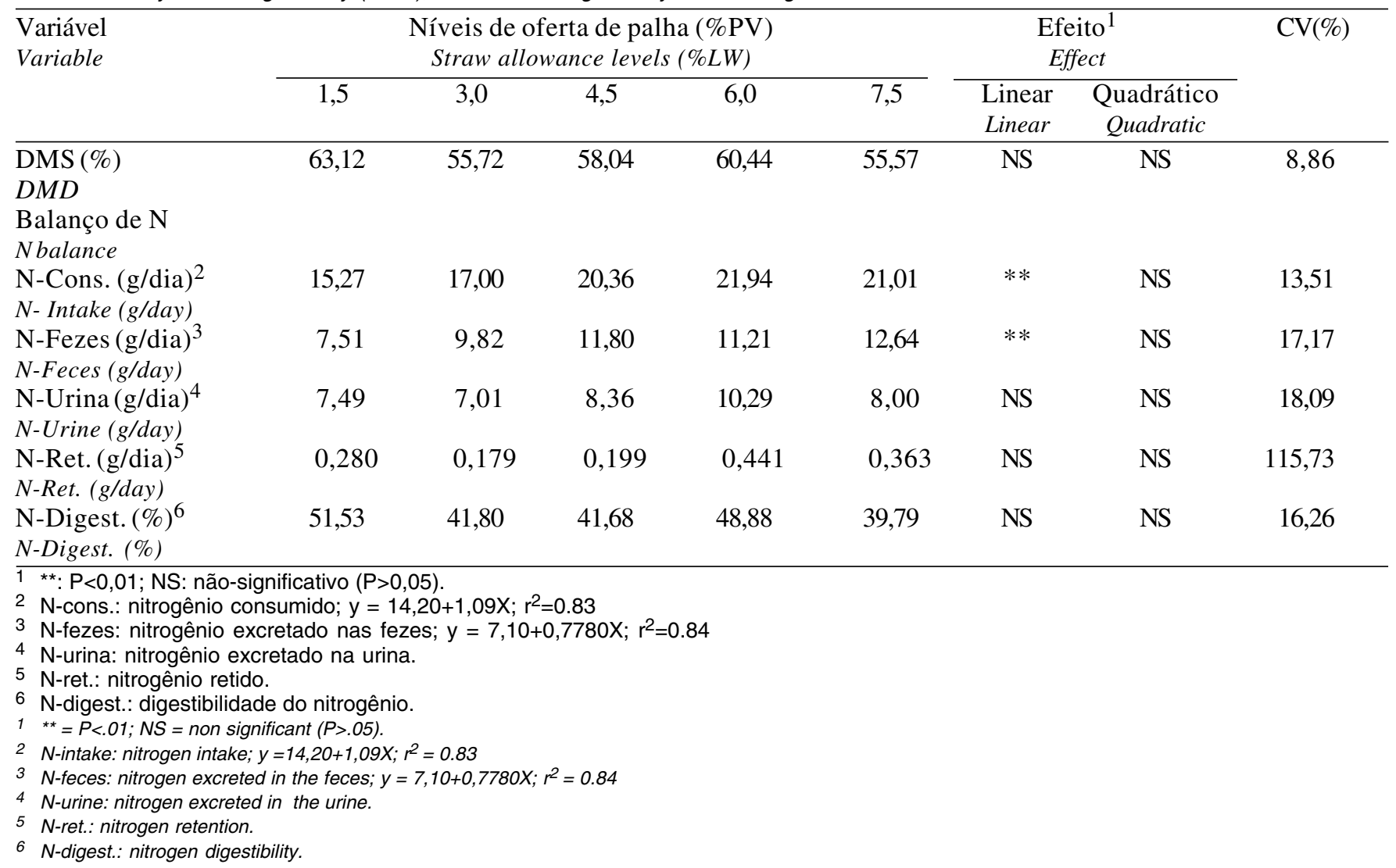

o motivo da ausência de efeitos dos níveis de oferta sobre a digestibilidade da MS. O valor médio para a digestibilidade da MS obtido na presente pesquisa está próximo daqueles obtidos por DJAJANEGARA e DOYLE (1989), 54,8 e 53,6\%, quando forneceram palha de arroz amonizada a ovinos, com ou sem infusão de enxofre e uréia no rúmen, respectivamente. Entretanto, os valores de DMS da palha de arroz amonizada variam consideravelmente em função das variedades utilizadas, conforme demonstraram IBRAHIM et al. (1989). Estes autores encontraram valores para digestibilidade in vitro da matéria orgânica da palha de arroz amonizada variando de 43,4 a 59,5\% .

$\mathrm{O}$ valor de N-retido obtido no presente experimento foi superior ao relatado por BENAHMED e DULPHY (1985), quando forneceram palha de trigo amonizada com uréia a ovinos adultos (-5,15 g/dia), mas inferior ao obtido por DJAJANEGARA e DOYLE (1989) (4,63 g/dia), que encontraram valores de consumo de $\mathrm{N}, \mathrm{N}$-fezes, $\mathrm{N}$-urina e digestibilidade aparente do $\mathrm{N}$ de 20,6 g/dia, 8,06 g/dia, 7,9 g/dia e $61,0 \%$, respectivamente. Estes resultados são muito próximos aos encontrados no presente estudo, exceto para digestibilidade do $\mathrm{N}$, que foi cerca de $37 \%$ superior $(44,7 \%$ vs $61,0 \%)$.

$\mathrm{O}$ aumento na oferta de palha, embora tenha elevado o consumo de $\mathrm{N}$, não foi traduzido em maior retenção de $\mathrm{N}$ pelos animais. Grande parte do aumento do $\mathrm{N}$ consumido devido à oferta foi excretado nas fezes.

A ausência de efeitos do nível de oferta sobre o $\mathrm{N}$ retido pode ser atribuído ao alto coeficiente de variação observado $(115,73 \%)$ e à própria característica deste tipo de experimento, uma vez que este valor reflete apenas a diferença entre o $\mathrm{N}$ consumido e o excretado, mas não revela nenhuma informação sobre a distribuição do $\mathrm{N}$ entre os tecidos e órgãos (MANATT e GARCIA, 1992). Esses autores argumentaram que o equilíbrio entre o $\mathrm{N}$ excretado $\mathrm{e}$ o consumido pode ser obtido em diferentes níveis de consumo de $\mathrm{N}$, mesmo nas situações em que alguns tecidos não estejam recebendo quantidades adequadas de N. Isto ocorre, provavelmente, porque o metabolismo animal altera as fontes corporais lábeis de $\mathrm{N}$, dependendo do nível de consumo de $\mathrm{N}$.

Um exemplo seriam as glândulas endócrinas, cuja demanda de $\mathrm{N}$, frente à magnitude dos valores de 
Rev. bras. zootec.

balanço, seria insignificante, mas que poderiam ser afetadas consideravelmente pelo consumo de $\mathrm{N}$ (MUNRO, 1985).

Consumo de matéria seca e matéria seca digestível

À medida que se incrementou a oferta de palha, os consumos de matéria seca (CMS) e de matéria seca digestível (CMSD) aumentaram (Figura 1), segundo as equações a seguir:

$\mathrm{CMS}=2,5\left[1-e^{(-0,6770 \mathrm{NO})}\right], \mathrm{r}^{2}=0,65 ; \mathrm{P}<0,01$

$\mathrm{CMSD}=1,4\left[1-e^{(-0,8033 \mathrm{NO})}\right], \mathrm{r}^{2}=0,43 ; \mathrm{P}<0,01$

Estas equações mostram que o consumo máximo esperado de MS e MSD de palha de arroz para os
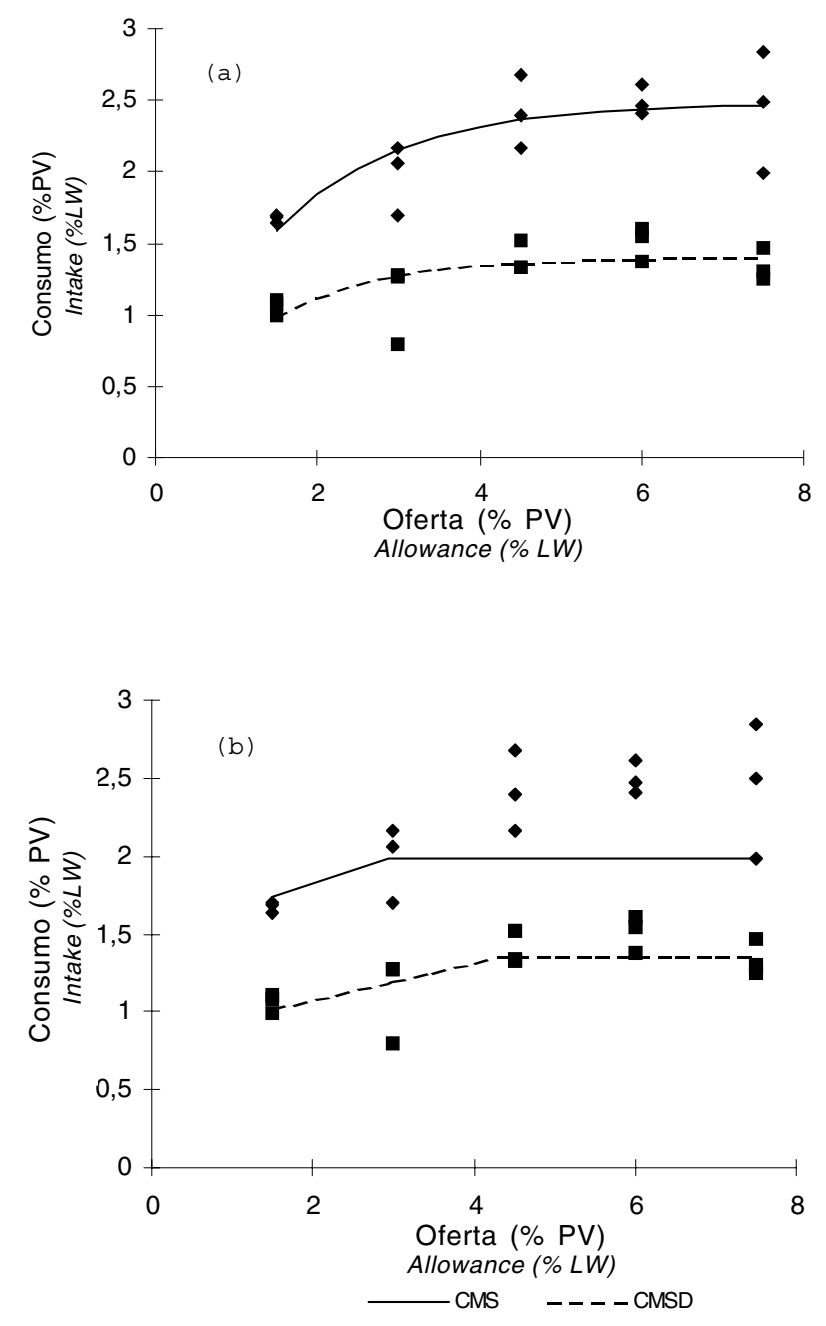

Figura 1 - Consumo de matéria seca (CMS) e de matéria seca digestível (CMSD) de palha de arroz amonizada, em função do nível de oferta ajustado ao modelo exponencial (a) e ao modelo de resposta linear com platô (b).

Figure 1 - Dry matter (DMI) and digestible dry matter (IDMD) intake of ammoniated rice straw, as affected by allowance levels and fitted to the exponential (a) and response-with-plateau models (b).
1171

animais utilizados no presente experimento foi de 2,5 e $1,4 \%$ do peso vivo (PV), respectivamente. Valor semelhante para consumo de MS foi obtido por WAHED et al. (1990) com palha de trigo não-tratada, fornecida à taxa de $9,0 \%$ PV a ovinos. FERNANDEZRIVERA et al. (1994) obtiveram valor de consumo potencial máximo de MS de 2,3\% em ovinos recebendo resíduos de Pennisetum glaucum.

A determinação do nível crítico de fornecimento de palha foi obtido a partir das seguintes equações (Figura 2):

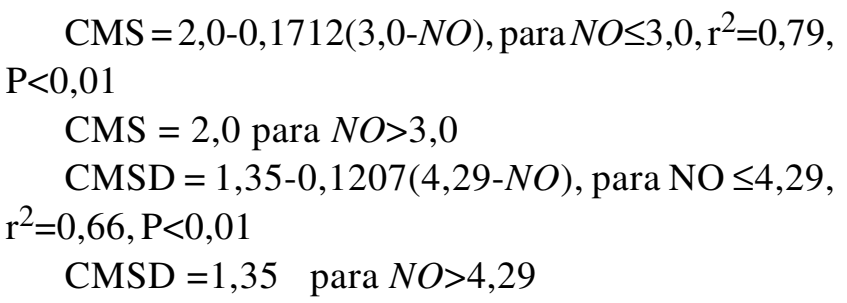

Estas equações indicam que incrementos consideráveis no consumo de MS foram obtidos com aumentos na oferta da palha até o nível de 3,0\% PV. A partir deste nível, os aumentos no consumo de MS foram inexpressivos ou ausentes. Já incrementos no consumo de MSD ocorreram até 4,3\% PV.

Os valores obtidos por FERNADEZ-RIVEA (1994) para o nível crítico de oferta foram de 2,6 e

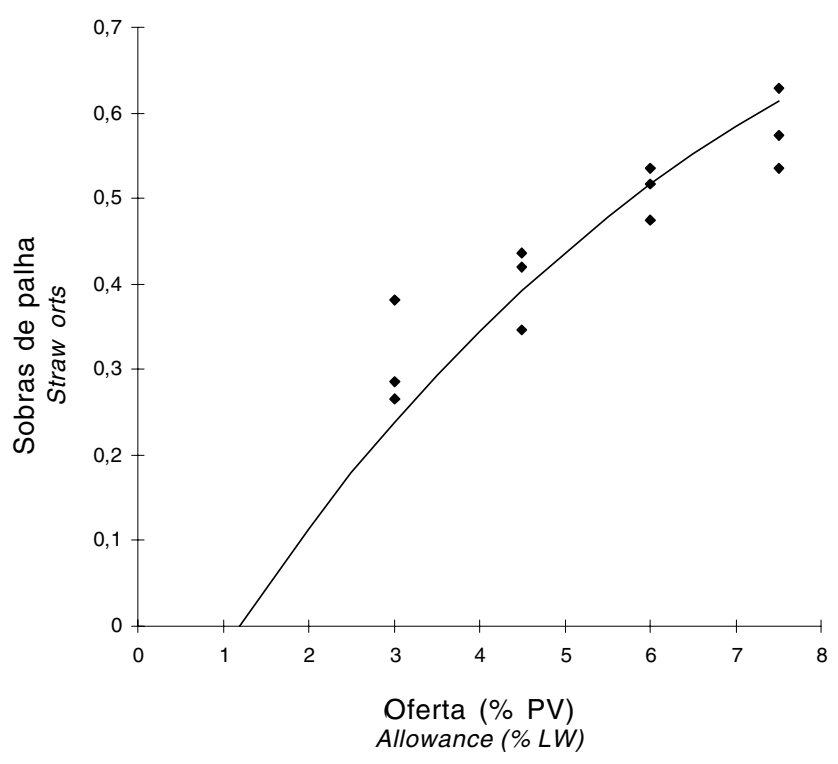

Figura 2 - Efeito dos níveis de oferta de palha de arroz amonizada na proporção de alimento rejeitado (sobras) por ovinos.

Figure 2 - Effect of allowance levels of ammoniated rice straw on the proportion of refused feed by sheep. 
3,1\% PV para o consumo de matéria seca e matéria orgânica digestível, respectivamente.

Estes resultados, além de indicarem aumentos no consumo de palha, quando a oferta aumenta, evidenciam que os animais consomem dietas de melhor qualidade nos níveis mais elevados de oferta, uma vez que o nível crítico de oferta, no presente experimento, para CMSD foi consideravelmente superior àquele para CMS, embora não tenha sido evidenciado efeito da oferta sobre DMS (Tabela 1).

A relação entre os níveis de oferta e as respectivas sobras foi expressa pela equação (Figura 2):

SMS $=1-e^{[-0,1510(\mathrm{NO}-1,196)]}$, para $N O>1,196$; $\mathrm{P}<0,0001, \mathrm{r}^{2}=0,93$

e

SMS $=0$, para $N O \leq 1,196$

Para os níveis críticos de oferta de palha, 3,0\% PV para CMS e 4,3\% PV para CMSD, as sobras de MS foram de 23,8 e 37,4\%, respectivamente. Estes valores são consideravelmente maiores aos 15,0 a $20,0 \%$, normalmente considerados como suficientes para se determinar o consumo voluntário em animais ruminantes (MINSON, 1990). Comportamento semelhante ao obtido na presente pesquisa foi relatado por FERNANDEZ-RIVERA et al. (1994) e BOSMAN et al. (1995).

A resposta do VPA aos níveis de oferta de palha é mostrada na Figura 3. Quanto maior o valor desta variável, maior será a quantidade de MS digestível destinada para fins produtivos, além das exigências de mantença, por unidade de palha fornecida. Pode-se verificar que a amplitude de valores é considerável, sendo que o máximo valor de VPA, 0,0994, seria obtido com oferta de $123,05 \mathrm{~g} / \mathrm{kg} \mathrm{PV}^{0,75}$ de MS de palha, o que representaria cerca de 4,4\% PV animal. Este nível de oferta é muito próximo ao nível crítico de oferta observado para CMSD (4,3\% PV).

Ofertas acima de $123,05 \mathrm{~g} / \mathrm{kg} \mathrm{PV}^{0,75}$ reduziram o VPA, devido ao aumento excessivo das sobras e pouca resposta no incremento do consumo de MSD. Por outro lado, ofertas inferiores reduziram o VPA em função da redução no consumo de MSD.

Assim, quando se desejar maximizar o ganho em peso dos animais, recomendam-se ofertas de 123,05 $\mathrm{g} / \mathrm{kg} \mathrm{PV}^{0.75}$. Se o objetivo principal é garantir consumo de MSD para atender a mantença dos animais, valores inferiores a $123,05 \mathrm{~g} / \mathrm{kg} \mathrm{PV}^{0,75}$ podem ser adotados. Ofertas superiores não são recomendadas, uma vez que resultaria desperdício de palha.

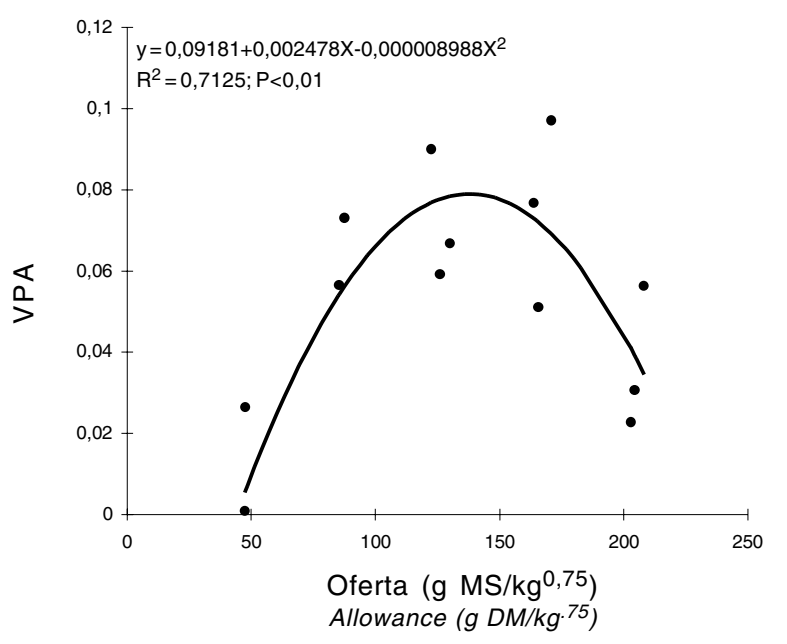

Figura 3 - Efeito dos níveis de oferta de palha de arroz amonizada no valor para a produção animal (VPA) em ovinos.

Figure 3 - Effect of allowance levels of ammoniated rice straw on the value for animal (VAP) production in sheep.

\section{Conclusões}

O nível de oferta de palha de arroz amonizada não afetou a digestibilidade da MS e a digestibilidade e balanço do N.

Oconsumo e excreção de $\mathrm{N}$ nas fezes incrementaram linearmente com o aumento na oferta de palha.

O consumo potencial máximo de MS e MSD foi de 2,5 e $1,4 \% \mathrm{PV}$, respectivamente.

Decréscimos consideráveis no consumo de MS e MSD ocorrem em níveis de oferta abaixo de 3,0 e $4,3 \% \mathrm{PV}$, respectivamente.

Para maximizar o desempenho animal por unidade de palha fornecida, recomenda-se oferta de $123,1 \mathrm{~g} / \mathrm{kgPV}^{0,75}$.

\section{Referências Bibliográficas}

ASSOCIATION OF OFFICIAL ANALYTICAL CHEMISTS AOAC. 1990. Official methods of analysis. 15.ed. Arlington, VA. $1094 \mathrm{p}$.

BENAHMED, H., DULPHY, J.P. 1985. Note sur la valeur azotée de fourrages pauvres traités par l'urée ou l'amoniac. Ann. Zootech., 34:335-346.

BOSMAN, H.G., VERSTEEGDEN, C.J.G.M., ODEYINKA, S.M. et al. 1995. Effect of amount offered on intake, digestibility and value of gliricidia sepium and Leucaena leucocephala for West African Dwarf goats. Small Rumin Res., 15:247-256. 
DAMASCENO, J.C., PRATES, E.R., PIRES et al. 1994. Efeito de níveis e formas de aplicação de uréia sobre a qualidade da palha de trigo. Rev. Unimar, 16(1):137-147. (Suplemento)

DJAJANEGARA, A., DOYLE, P.T. 1989. Urea supplementation compared with pretreatment. 1. Effects on intake, digestion and live-weight change by sheep fed rice straw. Anim. Feed Sci. Tech., 27:17-30.

FERNANDES-RIVERA, S., MIDOU, A., MARICHATOU, H. 1994. Effect of food allowance on diet selectivity and intake of pearl millet (Penniseton glaucum) stove leaves by sheep. Anim. prod., 58:249-256.

IBRAHIM, M.N.M., TAMMINGA, S., ZEMMELINK, G. 1989. Effect of urea treatment on rumen degradation characteristics of rice straws. Anim. Feed Sci. Tech., 24:83-95.

MANATT, M.W., GARCIA, P.A. 1992. Nitrogen balance: concepts and techniques. In: NISSEN, S. Modern methods in protein nutrition and metabolism. San Diego, CA: Academic Press, p.9-85.

MINSON, J., 1990. Forage in ruminant nutrition. San Diego, CA: Academic Press Inc. 483p.

MUNRO, H.N.1985. Historical perspective on protein requirements: objectives for the future. In: BLAXTER, K., WATERLOW, J.C. (Eds.). Nutritional adaptation in man. London: John Libbey and Company. p.155-167.
NATIONAL RESEARCH COUNCIL - NRC. 1985. Nutrient requirements of sheep. 6.ed. Washington, DC.: National Academy Press. 99p.

OWEN, E., VELASQUEZ, J.E. 1992. A grazing approach to stall-feeding crop residues and other low-quality forages to ruminants. In: TEIXEIRA, J.C., NEIVA, R.S. (Eds.). SIMPÓSIO INTERNATIONAL DE RUMINANTES, Lavras, 1992. Anais... Lavras: SBZ, p.65-85.

SNEDECOR, G., COCHRAM, W.G. 1989. Statistical methods. 8.ed. Ames: The Iawo State University Press. 503p.

WAHED, R.A., OWEN, E., NAATE, M. et al.. 1990. Feeding straw to small ruminants: effect of amount offered on intake and selection of barley straw by goats and sheep. Anim. Prod., 51:283-289.

Recebido em: 02/10/1998

Aceito em: 27/02/2000 